\title{
Sustainable Development of Water Conservancy Economy Under New Situation
}

\author{
Yu Liu \\ University of Science \& Technology of China, Hefei, China.
}

How to cite this paper: Yu Liu. (2021) Sustainable Development of Water Conservancy Economy Under New Situation. Advance in Sustainability, 1(1), 17-21. DOI: $10.26855 /$ as.2021.07.004

Received: June 2, 2021

Accepted: June 28, 2021

Published: July 14, 2021

*Corresponding author: Yu Liu, University of Science \& Technology of China, Hefei, China.

\begin{abstract}
In today's era, water resources are particularly critical, which have a certain impact on various industries. But in terms of the actual situation of water resources, it is not optimistic, no matter the reserves of water resources, or the use of water resources, more or less there are certain problems. Some areas have water shortage, and some areas have water pollution, these are not conducive to the efficient use of water resources, and then affect the development of water conservancy economy. This paper will discuss the specific use of water resources, analyze the existing problems and put forward targeted solutions in order to promote the development of water conservancy.
\end{abstract}

\section{Keywords}

Under the new situation, Water conservancy economy, Sustainable development

\section{Introduction}

In today's society, the problem of lack of water resources is very serious, and it also needs to be solved urgently. Moreover, in the development of The Times, the industrial development momentum is good, the scale of industrial development continues to expand, leading to the problem of water pollution is increasingly serious. The protection and construction of water resources is more important, in this aspect, need to increase economic investment, so the government attaches more importance to the development of water conservancy economy. From the perspective of social development trend, it is necessary to promote the sustainable development of water conservancy economy. The present situation of development of water conservancy in China, presents the good development momentum, but after on the concrete analysis, found that due to various reasons, led to the construction of water conservancy economy there is a lot of legacy, this article will carry on the discussion, put forward solutions, promote the sustainable development of water conservancy economy under the new situation.

\section{The importance of realizing sustainable development of water conservancy economy}

The sustainable development of water conservancy economy in the new situation is in line with the development trend of the society, and at the same time, it is widely supported by the society. In the development of water conservancy economy, only by adhering to the sustainable development as the core can the water conservancy economy keep up with the pace of the development of The Times and not lag behind the development of The Times. Whether in China's economic society, or in the political field of our country, the scientific concept of development has always played an important role, which has been widely recognized by all sectors of society, people are also under its influence, in various aspects of the harvest is quite abundant. Therefore, in China's current economic and social development, sustainable development has become an inevitable trend. In social and economic development, water conservancy economy plays an important role and is also a part of social and economic development. Therefore, enterprises should make reasonable use of water resources based on the scientific concept of development. Only in this way can water conservancy economy keep pace with The Times, promote the development of related industries and accelerate the pace of economic development. 


\section{Problems in the construction and development of water conservancy economy}

\subsection{Lack of a sound water resources market system}

In social development, water resource is very important, not only has a significant impact on many industries, but also affects the entire ecosystem. From the point of view of the use of water resources, it deviates from the goal of social development, and fails to keep pace with the pace of the development of The Times, and fails to grow synchronously with economic development. Therefore, in order to improve the utilization rate of water resources, more scientific and reasonable use of water quality, according to the actual water use situation, formulate the goal of water conservation, strengthen the management of water resources, actively change people's concept of water, and then promote the development of water resources, so that water conservation is implemented. Pay attention to the application and management of water resources, and monitor the use of water resources, so that it can be effectively saved. Analyze the actual water use situation, so as to determine the development direction, form the water resources market system in line with the actual situation, and then make water conservancy and economy develop synchronously.

\subsection{Lack of effective water price standard}

In order to ensure the sufficient supply of water resources and improve its stability, it is necessary to formulate scientific and reasonable water price standard according to the actual water use situation, so as to unify the water price market and promote the further management of water resources. By standardizing the water price, we can better carry out sewage treatment and promote the development of economy and water resources. After the investigation of water resources, it is found that there is a discrepancy between the water price and the social water demand in China, which is not conducive to the construction of an economy-saving society. People generally lack the awareness of water conservation, which leads to the widespread occurrence of water resources waste and serious water resources waste.

\subsection{The water conservancy industry relies heavily on administrative control}

On the development of water conservancy in specific circumstances, the administrative control has great dependence, lead to water conservancy industry lack of binding and effective internal control, at the same time it is also a lack of participation in a market economy, the position in the market economy itself is a lack of correct understanding, but also not fully play the role of water conservancy economy in market economy, fully rely on administrative control. This will lead to a lot of problems in the development of water conservancy economy, which is not conducive to the development of water resources, but also an obstacle to the sustainable development of water conservancy economy.

\subsection{Lack of reasonable delivery system of economic support}

In the water conservancy industry, economic income is very important, which can promote the development of water conservancy industry and promote the development of water conservancy maintenance and control work. However, due to the rapid development of market economy, in the water conservancy industry, only the government's economic investment, which not only has a restrictive effect on the water conservancy industry, but also has a certain influence on the development of the water conservancy industry. The construction and maintenance of water conservancy is not accomplished overnight, but a long-term process with timeliness, which is less attractive to the social economy and cannot attract social investment, thus it is difficult to effectively construct the water conservancy economy market. Its water conservancy construction and now though, but management is too backward, lack of innovation, lead to water conservancy economy management exist certain difficulties in the new period, the lack of proper management, at the same time, the maintenance of water conservancy equipment problems, this is bound to have a significant impact on the development of water conservancy, and reduce equipment using time.

\subsection{Lack of financial support}

In the construction of water conservancy projects, the source of funds is lack of diversity, and the national finance is the main source of funds, which to a certain extent indicates that compared with other industries, the water conservancy construction funds are relatively single investment, investment channels are few. As for the water conservancy project itself, its construction process is more complex, and has a long construction period, and in the process of construction, some equipment has gradually aged. This not only caused the waste of manpower, material resources and financial resources, but also shortened the service life of the equipment, and it is difficult to achieve sustainable development of China's water conservancy economy.

\section{Strategies for sustainable development of water conservancy economy}

\subsection{Improve the water rights mechanism}

In order to promote the sustainable development of water conservancy economy, it is necessary to perfect the relevant water 
right mechanism, which can provide the system guarantee for the development of water conservancy economy. In the process of perfect water right system, need according to the usage of water resources, to determine if it can be for public use, and to innovate and improve the mechanism of water rights, clear water resources use right and ownership, will both separations, can proper use of water resources, continued to strengthen water equipment, so that the water use efficiency increased. At the same time in the process of formulation mechanism of water rights, should be consistent with the trend of social development, through the use of income rights, constantly to perfect the related mechanism, pay attention to the market economy, the water conservancy economy into market economy, and moving parts and access to a market economy, so that the market economy under the premise that the law allows, can reasonably use of water resources. By combining the market economy with water conservancy economy, the market can better develop water resources, create water resources in abundant ways, better control the water rights of water resources, innovate the development and utilization of water resources, and promote the sustainable and stable development of water resources. Based on water conservancy economy to drive the development of related industries, improve the benefits of market economy, maximize the role of water resources, improve the social benefits of water resources.

\subsection{Establish a systematic water price management system}

In recent years, due to the further development of industry and agriculture, the social demand for water resources is more and more large, the consumption of water resources is also more and more large, resulting in the increasing shortage of water resources, the demand exceeds the supply. In this case, advocate water conservation, the establishment of water conservation system, continuous innovation and improvement of this system, and then promote the further development of water resources. In water resources management, we should realize the importance of water price management, and make clear the role of water price management, according to the actual situation of the water price scientific and reasonable adjustment, and then effectively control water resources. As for the water price itself, the low price has little impact on the production cost of enterprises. Therefore, industrial enterprises pursuing profit maximization generally do not pay attention to the problem of water resources, but only pay attention to the production efficiency and product quantity, which is bound to be a kind of indulgence for these enterprises and do nothing for the waste of water resources. Through effective control of water price, the production of some enterprises can be better regulated. These enterprises have a high consumption of water resources and lack of awareness of water conservation. The control of water price can increase the production cost of these enterprises, and make the management consciously use water resources as little as possible in order to save costs, so as to enhance people's awareness of water saving and realize the sustainable development of water resources. At the same time, in agricultural production, also need to pay attention to the control of water prices. Water is abundant in some areas, which is not a cost to farmers, so it is used indiscriminately and may lead to waste. In view of this situation, an irrigation mechanism suitable for agriculture should be established, the irrigation water for agricultural products should be reasonably controlled, and the price of water resources should be reasonably adjusted. In the case of agricultural water, the water consumption for crop production should be set according to the actual water consumption of each agricultural product, and prices should be raised when the water consumption exceeds a certain range. In this way, farmers' agricultural irrigation will not be affected on the whole, but farmers can have a correct understanding of the importance of water resources and pay attention to water conservation.

\subsection{Expand ways of economic investment in water conservancy}

In the water conservancy industry, it is very important to expand the way of water conservancy economy delivery. In order to broaden the work of water conservancy economy raising and better govern and control the economy, the way of water conservancy economy delivery in the new era is diversified. Based on the government's economic investment, it constantly attracts social investment, and forms the water conservancy economic investment system on this basis. Therefore, in the process of rational use of the market economic mechanism, it is necessary to increase the introduction of social economic delivery channels, so as to promote the further development of water conservancy economy. Our government attaches great importance to the investment of water conservancy economy, and also has certain means and strategies of economic subsidy. In water resources management, increase investment in economic quantity is necessary, such ability can make a water management under the new times more reasonable standard, make it get better development in the market, change the traditional management strategy, refused to pay attention to construction and management, but management and construction, water conservancy construction in order to make the good development of resources.

\subsection{Strive to change the unfavorable situation of water conservancy in China}

In order to realize the sustainable development of water conservancy economy, it is necessary to fully analyze the development status of water conservancy and economy and change the historical status quo. In the context of the specific development of the our country water conservancy economy, due to its late start, low starting point, so both in management idea, or is in the 
management system, there are some problems in such aspects as management mode, and the planned economy has great influence to the enterprise, sources of funds is too single, just rely on the state financial subsidies, it will produce certain limits to the development of water conservancy economic System, hinder the development pace of water conservancy economy. And in many parts of the water conservancy economy development idea is too backward, still the traditional concept of development, adhere to the development after the first treatment, and for the sustainable development of water conservancy economy lack of correct understanding, also did not realize its importance at the same time, this causes the water current economic development in China is not optimistic, is still in a relatively backward stage. Therefore, in view of the above series of disadvantages, we should fully analyze the problems, and then put forward solutions, so as to achieve the sustainable development of water conservancy economy.

First, on the specific development of the domestic water sufficient analysis, on this basis to establish the corresponding management mechanism, and according to the actual application situation continued to improve, implement the responsibility system, clear unit and related responsibility of the individual, it helps to strengthen the sense of responsibility of individuals or units, to implement it. At the same time, we should also establish a sound supervision mechanism. In the development of water conservancy, supervision is very important. Only with a perfect supervision mechanism can we urge relevant employees to work better, achieve reasonable management of water conservancy and achieve sustainable development of water conservancy economy.

Second, increase the intensity of capital input and provide financial support for the development of water conservancy by means of fiscal appropriation or the establishment of special funds. At the same time, in the process of developing water conservancy economy, the state and economy should formulate corresponding laws and regulations according to the specific situation of water conservancy development, so that the management of water conservancy economy can be guaranteed by system and tend to be standardized.

Third, improve the employment system of water conservancy departments. In order to realize the further development of water conservancy economy, water conservancy talents are necessary. Therefore, the water conservancy department should recruit excellent water conservancy talents according to the actual situation of the department, adopt reasonable ways to select talents and introduce high-quality water conservancy talents, so as to promote the development of water conservancy economy. In addition, within the department, the working ability of employees should be assessed, and the working ability of employees should be clarified, and the employees with poor working ability should be encouraged to quit. For employees with good working ability, training should be intensified to constantly improve their working ability and make them better qualified for related work. At the same time, in order to improve the enthusiasm of employees and promote the development of water conservancy, it is necessary to perfect the performance evaluation system with clear rewards and punishments, so as to realize the personal value of employees, promote the development of water conservancy and realize the sustainable development of water conservancy economy under the new situation. Finally, as far as water conservancy economic development itself is concerned, it is not only related to related industries, but also closely related to economic society. Therefore, the relevant departments should strengthen the publicity of water conservancy economy through the Internet and pay attention to the comprehensive participation, so as to form a healthy and sustainable development model of water conservancy economy.

\subsection{Strengthen reform and innovation}

In the new period, in order to make the sustainable development of water conservancy economy become a reality, it is necessary to keep up with the pace of the development of The Times and strengthen the reform and innovation. Combined with the development of China's economy and society, based on the economic functions of the government, such as market mechanism means, macro-control and so on to optimize the reform of water conservancy economy. In the tide of the development of The Times, new challenges emerge one after another. When we are faced with new challenges, we should pay attention to the innovation of methods and use new methods to deal with new problems. For example, pay attention to the operation and maintenance of water conservancy facilities, pay attention to the management of water conservancy facilities, so that the utilization rate of water conservancy facilities can be effectively improved. Increase the basic water price, let people realize the value of water and the importance of water through water price. It is also necessary to strengthen the awareness of water conservation among the masses, and we can guide the masses to set up the awareness of water conservation through a variety of reform ways, so as to alleviate the problem of water shortage and serious water pollution as far as possible, and realize the sustainable development of water conservancy economy.

\subsection{Actively build a perfect water resources market}

As far as water resources themselves are concerned, they have strong comprehensiveness. From the perspective of the development and utilization of water resources in the past, there are some problems that only pay attention to the early investment, but do not pay attention to the quality management, resulting in the income of water resources development is not con- 
sistent with the expectation. Therefore, in the new situation, we should follow the pace of The Times according to the actual situation, build a perfect water resources market, strictly in accordance with the relevant laws and regulations, so that the work of the relevant units to be implemented, and then reasonable development and utilization of water resources. For example, some areas have a relatively developed tourism industry, so local water conservancy projects can be developed to improve the economic benefits of water conservancy. In this process, the relevant departments should arrange high-quality personnel to supervise and manage it. Only in this way can we promote the development of China's water conservancy economy and realize the sustainable development of water conservancy economy under the new situation.

\subsection{Improve the supervision system of water conservancy economy}

In the development of market economy, the relevant system is very important. And each kind of market behavior needs to have the corresponding system. In the process of water conservancy economic development, it is necessary to perfect the supervision system so as to make better use of water resources. In this process, it is necessary to perfect the supervision system of water conservancy economy, so as to ensure the long-term and stable development of water conservancy economy operation. In the process of implementing and perfecting the relevant supervision system, it is necessary to coordinate the related contents of water conservancy ecology and water conservancy economy, estimate the capital input, and evaluate the output, so as to avoid the situation that the input exceeds the output as far as possible, and ensure the scientific and reasonable decision-making. In the process of perfecting the supervision system, it is necessary to adhere to the principle of adjust measures to local conditions, everything from set out actually, from the actual situation of the local study of water conservancy engineering, design of development of water conservancy projects in accordance with local policy, at the same time for the problems existing in the past, should actively to correct, to promote the sound development of water conservancy economy, these are the important content in the supervision and management. After that, it is necessary to increase the training of relevant personnel to help the development of water conservancy project economy, so that it can become an integral part of the national economy and play a greater role.

\section{Conclusion}

Water conservancy economy is very important, also is our country social economy important component. In the socialist market economy, it is necessary to promote the further development of water conservancy economy. Only in this way can we meet the needs of society and people and realize sustainable development. In terms of the actual development of water conservancy economy, there are still a variety of problems, hindering the development of water conservancy economy. In this paper, the water source of financial support of economic development is too single, backward management mechanism, the lack of scientific management idea and so on carries on the full analysis, based on this, puts forward the water conservancy economy development needs to perfect the mechanism of water right, to set up the system of water management system, perfecting the supervision system of water conservancy economy, in order to promote the further development of water conservancy economy, realize the sustainable development of water conservancy economy under the new situation and promote social prosperity and development.

\section{References}

[1] Yang Yibing. (2018). Suggestions on improving water conservancy economic management [J]. Modern Economic Information, 2018, (02): 68. (in Chinese)

[2] Wang Qingru. (2019). Analysis of sustainable development of water conservancy economy under new situation [J]. Consumer Guide, 2019, 25(21): 132. 